\title{
Effect of Glutaraldehyde on the Conformational Properties of Kluyveromyces lactis $\beta$-Galactosidase and Its Application to Sucrose Biosensor Preparation
}

\author{
Xiaobin Kang, Guangchang Pang*, Lihua Geng1, \\ Jiapeng Li, Haiqiong Song and Fang Wang \\ Tianjin Key Laboratory of Food Biotechnology, College of Biotechnology and Food Science, \\ Tianjin University of Commerce, Tianjin 300134, China \\ 'Ensoul Technology Ltd., \\ Room 603, No. 168, Guanganmenwai Street, Xuanwu District, Beijing 100055, China
}

(Received May 7, 2012; accepted July 9, 2012)

Key words: $\quad \beta$-galactosidase, glutaraldehyde, conformational change, sucrose biosensor, fluorescence spectroscopy, Kluyveromyces lactis

The effect of glutaraldehyde on the conformational properties of Kluyveromyces lactis $\beta$-galactosidase was determined. The optimum substrate of the enzyme interchanged from lactose to sucrose when it reacted with a certain concentration of glutaraldehyde. Its mechanism was studied by detecting the changes in fluorescence absorption. This is the first discovery that $\beta$-galactosidase can be converted to another kind of enzyme which can catalyze sucrose to produce glucose rather than lactose. On the basis of this phenomenon, an amperometric sucrose biosensor using $\beta$-galactosidase modified by glutaraldehyde as the immobilized enzyme and poly- $\beta$-cyclodextrin as the carrier was prepared. The response characteristic of the sucrose biosensor was also studied. Under optimum conditions, the current response had a linear relationship with the sucrose concentration in the range of $0-2 \mathrm{~g} / \mathrm{dL}$ with a correlation coefficient of 0.9996 and a response time of $<30 \mathrm{~s}$. The sucrose biosensor exhibited excellent diffusion and stability, and retained its sensitivity after $7 \mathrm{~d}$ of continuous use. This sucrose biosensor is expected to provide an effective and economical alternative for the quick and sensitive detection of sucrose in the food and beverage industries in the future.

\section{Introduction}

$\beta$-galactosidase (E.C.3.2.1.23), also called lactase, catalyzes the hydrolysis of $\beta$ (1-3)- $\beta$ (1-4) galactosyl bonds such as those present in lactose to yield glucose and galactose. ${ }^{(1,2)}$ In the past decade, the application of $\beta$-galactosidase to the hydrolysis of lactose in the dairy process under both free and immobilized conditions has received considerable

${ }^{*}$ Corresponding author: e-mail: pgc@tjcu.edu.cn 
attention, ${ }^{(3)}$ and has found significant applications in enhancing the sweetness, solubility, flavor and digestibility of dairy products. ${ }^{(4)}$ Nowadays, the transferase activity of $\beta$-galactosidase is also attracting the attention of researchers because the produced galacto-oligosaccharide (GOS) has a beneficial effect on the growth of desirable intestinal microflora such as Bifidobacteria. ${ }^{(5,6)}$

$\beta$-galactosidase can be found in nature in plants and animal organs as well as in large numbers of microorganisms, ${ }^{(7,8)}$ such as filamentous fungi, bacteria and yeasts. ${ }^{(8)}$ The major industrial $\beta$-galactosidases are derived from Kluyveromyces lactis, Kluyveromyces fragilis and Aspergillus niger. Although the enzymes derived from various microbial origins have different properties, such as molecular weight, protein chain length, and the position of the active site, the $\beta$-galactosidases have the same amino acid residue, glutamic acid, as their catalytic site. ${ }^{(9)}$

Enzyme immobilization has played a role in lactose hydrolysis in food industries since as early as the $1970 \mathrm{~s} .{ }^{(10)}$ Several techniques have been used for the immobilization of $\beta$-galactosidase and these have included entrapment, ${ }^{(11)}$ cross-linking, ${ }^{(12)}$ adsorption, ${ }^{(7,13)}$ embedding, ${ }^{(14)}$ electrochemical deposition ${ }^{(15)}$ or a combination of these methods. ${ }^{(8,16,17)}$ However, enzyme activity tends to decrease markedly as a result of immobilization using covalent bonds. ${ }^{(18)}$ Glutaraldehyde is the usual cross-linking reagent in enzyme immobilization. The immobilization of $\beta$-galactosidase on a certain carrier can be achieved by means of the Schiff's base reaction between the active groups of the carrier and the enzyme molecules to form covalent linkages. The enzyme is always affected by glutaraldehyde in the course of immobilization and some of its activity is lost as the operation time proceeds. What is peculiar is that although the $\beta$-galactosidase from Kluyveromyces lactis loses its lactose-hydrolyzing activity when in contact with a certain concentration of glutaraldehyde after a period of time, it will gain the ability to hydrolyze the sucrose, which is similar to lactose.

Sucrose is produced by many higher plants and commonly known as table sugar. It is one of the products of photosynthesis and is composed of fructose and glucose via an $\alpha-(1-2)$ link. Sucrose is widely used in the food and beverage industries, so it is important to have a fast, simple and cost-effective method that can be used for the determination of sucrose in food and drink. Conventional methods such as wet biochemical analysis and liquid chromatography (LC) are laborious, and well-trained technicians are needed. With the popularity of biosensor study, the sucrose biosensor was invented; in particular, the enzyme-based sucrose biosensors are of interest for the achievement of simple and rapid measurement.

The purpose of this paper is to study the effect of glutaraldehyde on the conformational properties of Kluyveromyces lactis $\beta$-galactosidase by fluorescence spectroscopy $^{(19-21)}$ and its application to sucrose biosensor preparation. Fluorescence spectroscopy is an effective method of studying protein conformation. The intrinsic protein fluorescence changes, and through the observation of shifts in its wavelength, the characteristic of the solvent exposure of Trp residues, which always exist in the active site of the enzyme, provides important information on enzyme conformation. Moreover, an amperometric enzyme biosensor with high capability was prepared, which can be used for sucrose detection. 


\section{Materials and Methods}

\subsection{Reagents}

Glucose oxidase (GOD, $190000 \mathrm{U} / \mathrm{g}$ ) and Kluyveromyces lactis $\beta$-galactosidase (GAL, $\geq 3000 \mathrm{U} / \mathrm{mL}$ ) were obtained from Sigma-Aldrich (St. Louis, MO, USA) and used without further purification. Glutaraldehyde, sucrose, lactose, glucose, $\beta$-cyclodextrin $(\beta-C D)$ and other reagents were of analytical grade. Standard solutions of glucose and sucrose were prepared in distilled water. The buffer system is $0.2 \mathrm{M}$ potassium phosphate.

\subsection{Apparatus}

An SBA-40C glucose biosensor was purchased from Biology Research Institute of Shandong Province. It has two Pt electrodes as working electrodes and $\mathrm{Ag} / \mathrm{AgCl}$ electrodes as reference electrodes. Nuclear pore membranes $(0.45 \mu \mathrm{l})$ were purchased from Whatman, UK. A 970CRT fluorescence spectrofluorimeter was purchased from Shanghai Leng Guang Technology Co., Ltd.

\subsection{Effect of glutaraldehyde on free $\beta$-galactosidase}

The activity of free $\beta$-galactosidase from a Kluyveromyces lactis solution mixed with glutaraldehyde of various concentrations $(0.5,1.25,2.5$, and $5 \%$; v/v) was determined using the SBA-40C glucose biosensor with lactose and sucrose as its substrates. The protocol of the assay was in accordance with the user guide of the SBA-40C glucose biosensor.

The structural properties of $\beta$-galactosidase were determined by fluorescence measurements. $0.1 \mathrm{~mL}$ of $\beta$-galactosidase $(3000 \mathrm{U} / \mathrm{mL})$ was diluted to $10 \mathrm{~mL}$ and then mixed with $10 \mathrm{~mL}$ of $0.4 \%(\mathrm{v} / \mathrm{v})$ glutaraldehyde. The sample was stored in a water bath at $25^{\circ} \mathrm{C}$. Then, the sample was used to detect the fluorescence absorption. Fluorescence emission spectra between $300-400 \mathrm{~nm}$ were measured at $25^{\circ} \mathrm{C}$ with the $970 \mathrm{CRT}$ fluorescence spectrofluorimeter. Excitation was at $277 \mathrm{~nm}$ with a band pass of $4 \mathrm{~nm}$ for excitation and emission. The recording speed was $1 \mathrm{~nm} / \mathrm{s}$. The sample was placed in a rectangular quartz cuvette that was closed with a Dura-Seal polyethylene stretch film.

\subsection{Preparation of enzyme electrodes}

$\beta-C D$ is a cyclic oligosaccharide consisting of seven $\alpha$-D-glucose units connected through $\alpha-(1,4)$ linkages. The structure of these molecules is toroidal, with truncated cones containing an apolar cavity with primary hydroxyl groups lying on the outside and secondary hydroxyl groups inside. ${ }^{(22)}$ The hydroxyl groups of $\beta-\mathrm{CD}$ can be functionalized with hydrophobic or hydrophilic groups to further enhance the complexforming ability and selectivity towards certain analytes. ${ }^{(23)} 0.7 \mathrm{~g}$ of $\beta$-CD was dissolved in $10 \mathrm{~mL}$ of $0.2 \mathrm{M}$ sodium hydroxide solution containing $5 \%(\mathrm{v} / \mathrm{v})$ glutaraldehyde. Then, the solution was heated until the crystal ( $\beta$-CDP) precipitated, which was formed from poly $\beta-C D$ with glutaraldehyde by polycondensation. ${ }^{24)}$ Then, the sodium hydroxide that remained on the surface of the polymer was washed with distilled water. The multienzyme solution was made of $0.005 \mathrm{~g}$ of GOD, $0.01 \mathrm{~g}$ of BSA and $1 \mathrm{~mL}$ of GAL. 
$10 \mu \mathrm{L}$ of the multienzyme solution and $0.1 \mathrm{~g}$ of $\beta$-CDP carrying active free aldehydic groups were mixed together for 3-4 min. Then, the particulates absorbing the modified $\beta$-galactosidase were spread equally on the surface of two nuclear pore membranes, forming a sandwichlike enzyme membrane (see Fig. 1). When the enzyme membrane was immobilized on the surface of an electrode of the SBA-40C glucose biosensor, the sucrose biosensor was completed.

\subsection{Effect of cross-linking time with glutaraldehyde on specificity of immobilized $\beta$-galactosidase}

In accordance with the method described in $\S 2.4$, a series of enzyme biosensors, in which the multienzyme and $\beta$-CDP carrying active free aldehydic groups were mixed together for $10,30,50,80,100$, and $120 \mathrm{~min}$, were prepared. The activity of the immobilized $\beta$-galactosidase was determined using the SBA-40C biosensor with $1 \mathrm{~g} / \mathrm{dL}$ lactose and $1 \mathrm{~g} / \mathrm{dL}$ sucrose as its substrates.

\subsection{Response characteristic of sucrose biosensor}

The kinetic property of the sucrose biosensor based on the $\beta$-galactosidase modified by glutaraldehyde using poly- $\beta-C D$ as the carrier was studied using the SBA-40C biosensor by changing the concentration of sucrose from 0.2 to $1.0 \mathrm{~g} / \mathrm{dL}$ and the response time from 5 to $60 \mathrm{~s}$. The linear range of the sucrose biosensor was studied with standard sucrose solutions of varying concentrations. The storage stability was determined from the results of successive testing for $7 \mathrm{~d}$ ( 40 samples every day).

\section{Results and Discussion}

\subsection{Effect of glutaraldehyde on activity of free $\beta$-galactosidase}

The effect of glutaraldehyde on the activity of free $\beta$-galactosidase from Kluyveromyces lactis was studied, as shown in Fig. 2. The activity of $\beta$-galactosidase for hydrolyzing lactose decreased quickly after being mixed with the glutaraldehyde, and the rate of activity loss increased with the increasing glutaraldehyde concentration. After $10 \mathrm{~min}$, almost all of them were completely denatured. However, from Fig. 3, it can be seen that the activity of $\beta$-galactosidase for hydrolyzing sucrose increased in contrast to when it reacted with the glutaraldehyde, and its ability to hydrolyze sucrose clearly increased
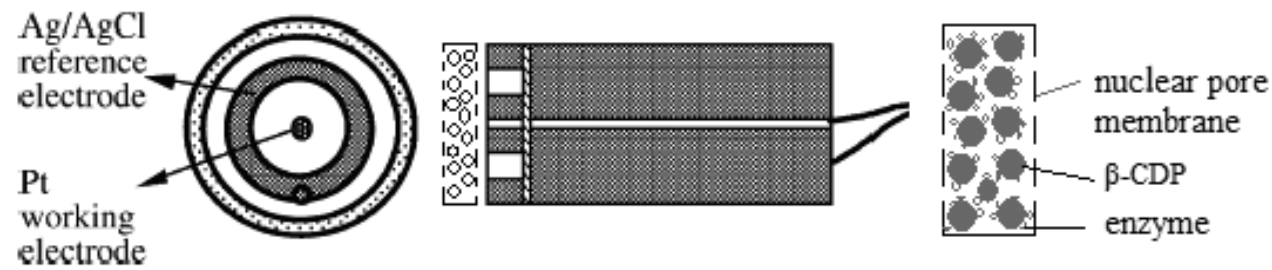

Fig. 1. Schematic representation of amperometric enzyme biosensor for sucrose. 


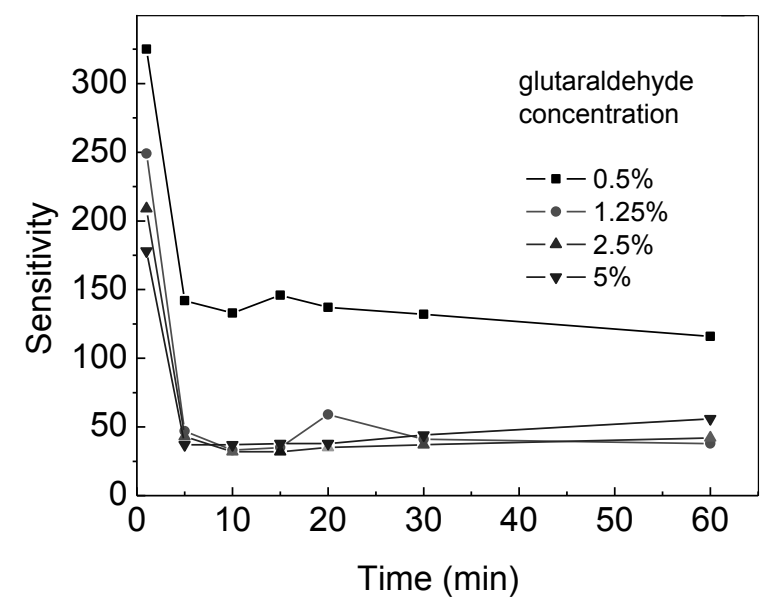

Fig. 2. Effect of glutaraldehyde on the activity of free Kluyveromyces lactis $\beta$-galactosidase using lactose as substrate.

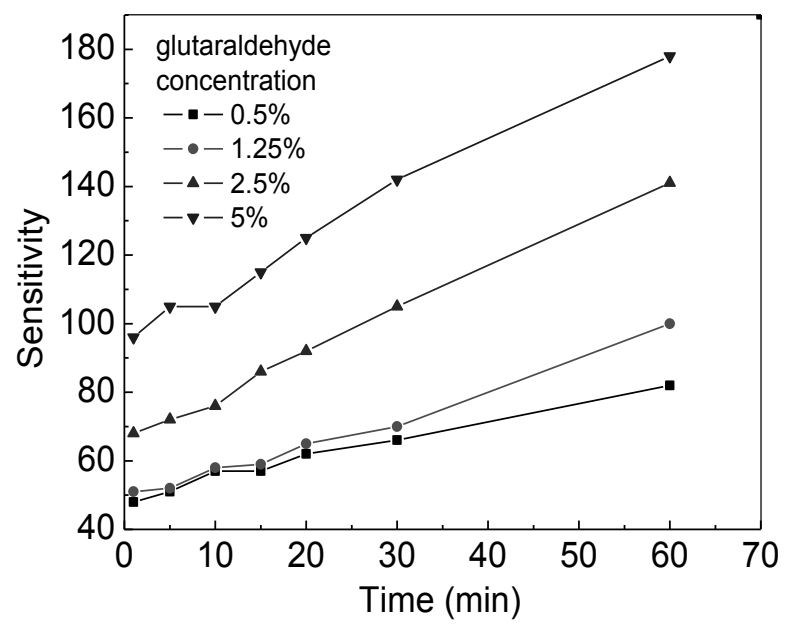

Fig. 3. Effect of glutaraldehyde on the activity of free Kluyveromyces lactis $\beta$-galactosidase using sucrose as substrate.

with increasing glutaraldehyde concentration and with time, which suggests that the conformation of the $\beta$-galactosidase active site had changed.

\subsection{Effect of glutaraldehyde on structural properties of free $\beta$-galactosidase}

The effect of glutaraldehyde on the structural properties of $\beta$-galactosidase from Kluyveromyces lactis was studied. As shown in Fig. 4, $\beta$-galactosidase shows a 


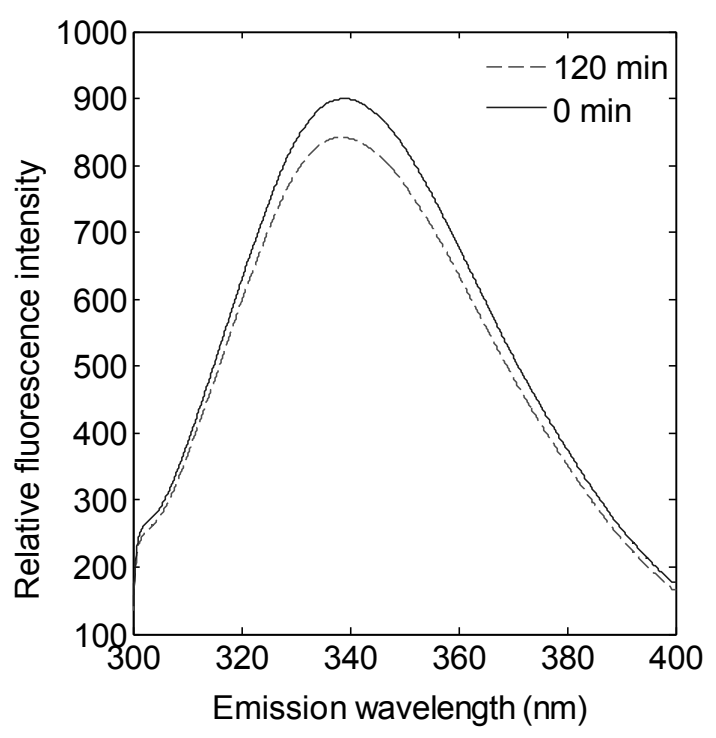

Fig. 4. Intrinsic fluorescence emission spectra of native free $\beta$-galactosidase in water solution.

maximum fluorescence emission intensity at $336 \mathrm{~nm}\left(\lambda_{\max }=336 \mathrm{~nm}\right)$ at $25^{\circ} \mathrm{C}$ in water. The value of $\lambda_{\max }$ did not change, and the fluorescence intensity decreased slightly after $120 \mathrm{~min}$, suggesting that the enzyme was stable in the testing environment without interference from other reagents. The relatively low value of $\lambda_{\max }$ thus reflects a rather apolar environment of Trp residues. ${ }^{(25)}$ For comparison, the maximum fluorescence of Trp in a neutral water solution is about $350 \mathrm{~nm}$, and in a hydrophobic environment, such as the interior of a folded protein, the Trp emission occurs at a shorter wavelength (indole shows an emission of $320 \mathrm{~nm}$ in hexane). ${ }^{(26)}$ Most of the Trp residues thus appear to be buried inside $\beta$-galactosidase in a hydrophobic environment. As shown in Fig. 5, when $\beta$-galactosidase was mixed with $0.4 \%$ glutaraldehyde, the maximum emission instensity was redshifted to near $340 \mathrm{~nm}$ and the fluorescence intensity decreased over time. After $120 \mathrm{~min}$, the shift of the maximum and the decrease in the fluorescence intensity were still proceeding. Both the redshift and quenching of the emission provide evidence that the environment of the Trp residues (see Fig. 6) had changed, leading to a polarity increase in this environment. The center of the spectral mass is indicative of the solvent exposure of Trp. Solvent relaxation around the excited state dipole of the Trp leads to a lowering of the energy of the excited state, and thus, to a less energetic, or redshifted, emission. ${ }^{(27)}$

The mechanism of lactose hydrolysis was first described by Wallenfels and Malhotra, ${ }^{(28)}$ who used the lactase from E. coli, and has been described in many review articles. ${ }^{(29)} \beta$-galactosidase catalyzes the hydrolysis of $\beta$-1,4-glycosidic bonds using a two-step, double-displacement mechanism involving the formation and breakdown of 


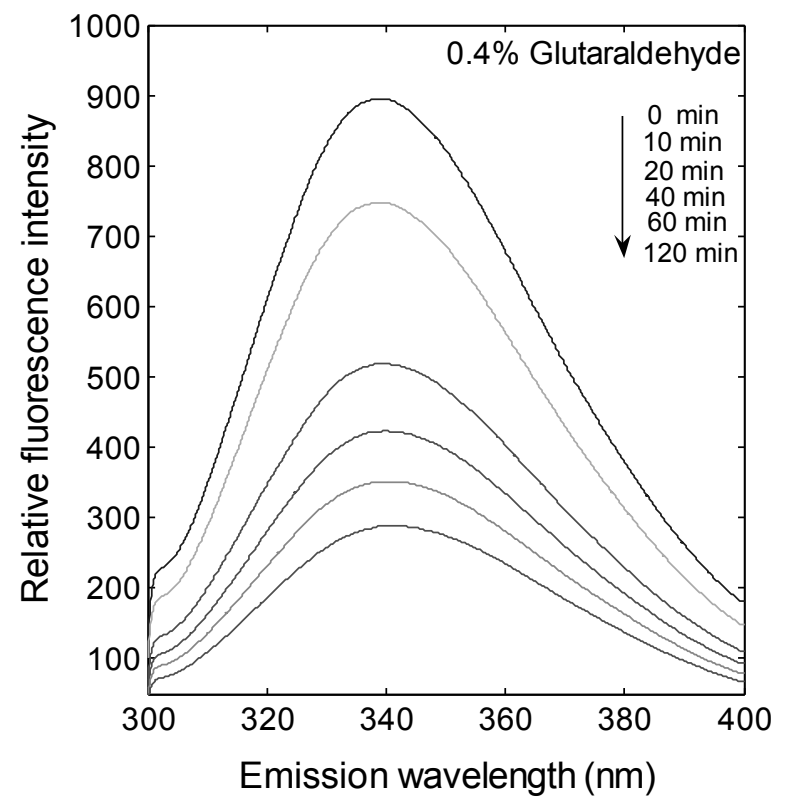

Fig. 5. Intrinsic fluorescence emission spectra of free $\beta$-galactosidase in $0.4 \%$ glutaraldehyde solution.
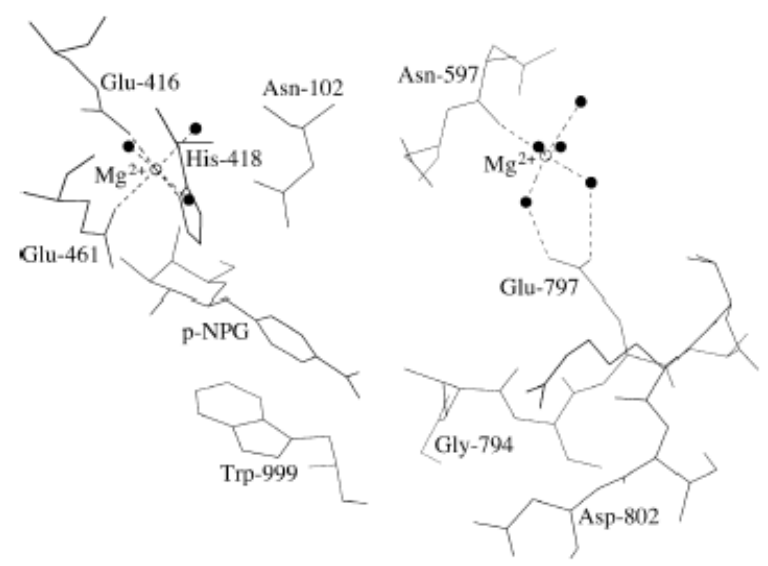

Fig. 6. Structure of $\beta$-galactosidase active site. 
a covalent glycosyl-enzyme intermediate via oxocarbenium ionlike transition states. It has become clear that the enzymatic hydrolysis of the glycosidic bond of lactose takes place via general acid catalysis that requires two critical residues, i.e., a proton donor and a nucleophile/base. The hydrolysis of $\beta$ (1-3) and $\beta$ (1-4) galactosyl bonds in oligosaccharides takes place through general acid catalysis, wherein Glu-482 is the proton donor and Glu-551 is the nucleophile. ${ }^{(9,30)}$ Some studies revealed that the glutamic acid residues both in the active site of $\beta$-galactosidase and invertase play a key role in catalyzing the reaction. ${ }^{(31,32)}$ Thus, the changes in their sites will affect the activity of the enzyme markedly. It is presumed that the size of the active site of $\beta$-galactosidase decreased after it reacted with glutaraldehyde, which linked the two adjacent Asn residues (Asn102, Asn597), resulting in the conformation becoming more suitable for sucrose hydrolysis, which can first form an enzyme-fructose complex with simultaneous glucose liberation. ${ }^{(9)}$

\subsection{Effect of cross-linking time with glutaraldehyde on specificity of immobilized $\beta$-galactosidase}

The results obtained from the study of the effect of cross-linking time with glutaraldehyde on the specificity of immobilized $\beta$-galactosidase are illustrated in Fig. 7. It is observed that with increasing cross-linking time, the activity of the immobilized $\beta$-galactosidase membrane with sucrose showed a rapid increase, and became maximum at $80 \mathrm{~min}$, whereas with lactose, it showed a marked decrease, and basically lost its activity after $80 \mathrm{~min}$. Thus, the optimum cross-linking time with glutaraldehyde was 80 min for obtaining the maximum activity with sucrose from the allosteric $\beta$-galactosidase. This may be explained by the fact that the active center structure of $\beta$-galactosidase is affected by the cross-linking time with a certain concentration of glutaraldehyde and

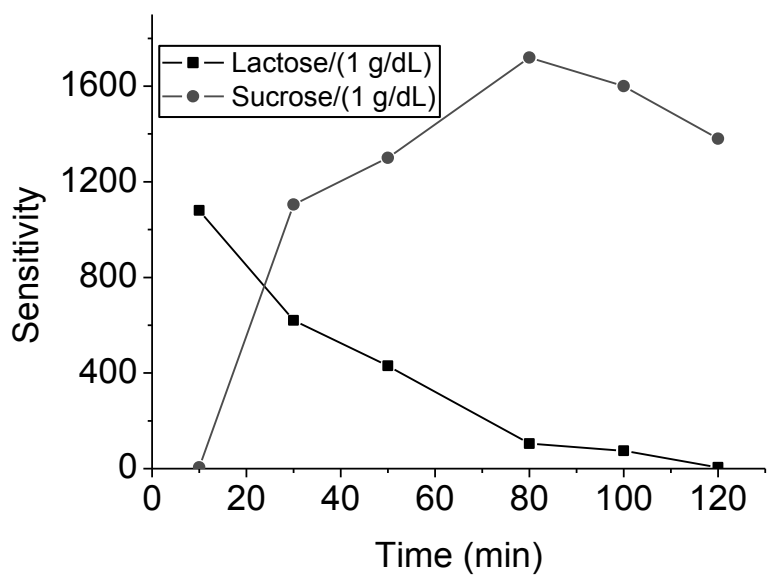

Fig. 7. Effect of cross-linking time with glutaraldehyde on the specificity of immobilized $\beta$-galactosidase. 
causes a change in the specificity of $\beta$-galactosidase. To the best of our knowledge, this has not been observed in any other study.

\subsection{Kinetic property of sucrose biosensor based on $\beta$-galactosidase modified} by glutaraldehyde using poly- $\beta-C D$ as carrier

The process of the sucrose hydrolysis reaction catalyzed by the $\beta$-galactosidase modified by glutaraldehyde can be seen directly from the kinetic property of the biosensor. On the basis of which, we can determine the best end point of the reaction and determine the diffusion property of the enzyme membrane. As shown in Figs. 8 and 9, the sucrose biosensor has satisfactory kinetic properties; it has a high sensitivity and a highly linear relationship with sucrose concentration from 0.2 to $1.0 \mathrm{~g} / \mathrm{dL}$ at all time points. In particular, at $20 \mathrm{~s}$, the correlation coefficient is more than 0.9999 . This suggested that the carrier made of poly- $\beta-C D$ can ably capture the enzyme and that the enzyme membrane has an excellent diffusion property.

\subsection{Linear range of sucrose biosensor}

Samples including a series of standard sucrose solutions with different concentrations were detected using the sucrose biosensor (see Fig. 10). The results showed that the biosensor has a good linear relationship with the sucrose concentration in the range of $0-3 \mathrm{~g} / \mathrm{dL}$. In particular, in the range of $0-2 \mathrm{~g} / \mathrm{dL}$, the corresponding equation was $Y=$ $-7.2447+1065.6022 c(\mathrm{~g} / \mathrm{dL})$ and the correlation coefficient reached 0.9996 ; thus, the sucrose biosensor is expected to be highly applicable for sucrose detection.

\subsection{Stability of sucrose biosensor}

The sucrose biosensor was continuously tested for $7 \mathrm{~d}$ ( 40 samples every day); the results (Fig. 11) showed that the sucrose biosensor with poly- $\beta-C D$ as the carrier had

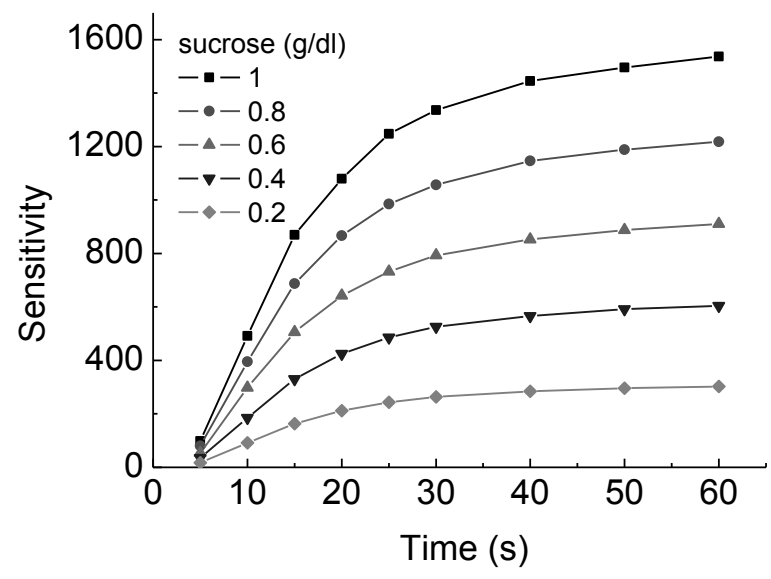

Fig. 8. Kinetic property of the sucrose biosensor. 


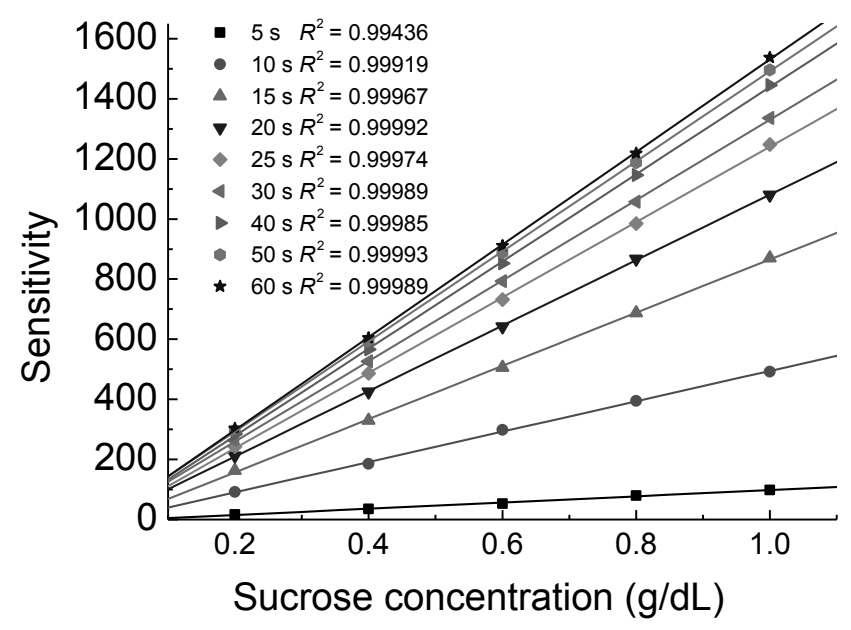

Fig. 9. Linear relationship at every time point.

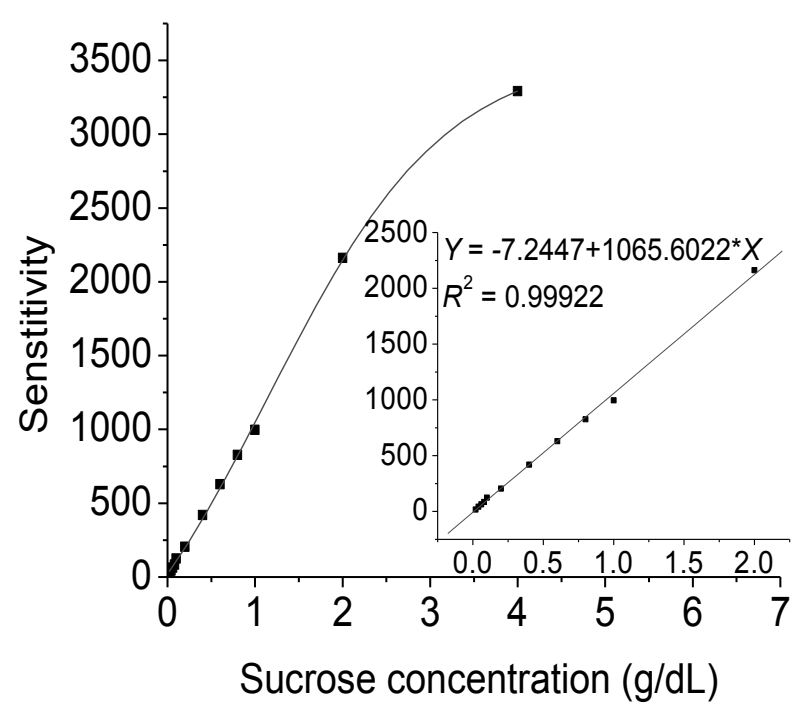

Fig. 10. Linear range of the sucrose biosensor.

good stability; the response value to $1.2 \mathrm{~g} / \mathrm{dL}$ sucrose did not significantly decrease. This suggested that the conformation of $\beta$-galactosidase denatured by glutaraldehyde was sufficiently stable in this environment, where a balanced structure was formed between the enzyme and carriers, which can maintain the conformation of the enzyme active site. 


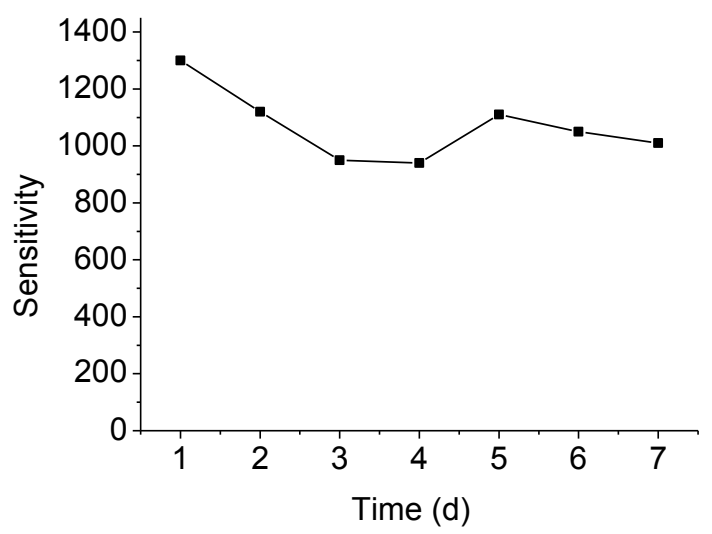

Fig. 11. Stability of the sucrose biosensor.

\section{Conclusions}

The effect of glutaraldehyde on the structural properties of Kluyveromyces lactis $\beta$-galactosidase was studied. An interesting phenomenon was first found, that is, the optimum substrate of $\beta$-galactosidase from Kluyveromyces lactis interchanged from lactose to sucrose when it reacted with $5 \%$ glutaraldehyde for $80 \mathrm{~min}$. The mechanism was studied using fluorescence absorption. The result showed that two Asp residues bordering on the activity center of the enzyme were linked by one molecule of glutaraldehyde, leading to the change in the active center conformation of $\beta$-galactosidase, which can be demonstrated from the change in the value of $\lambda_{\max }$ and the fluorescence intensity. The shrunk space is more suited for the fructose included in sucrose than the galactose in lactose. The interchange process has provided significant research experience for the modification of the active center and the transformation of the enzyme. On the basis of this phenomenon, a sucrose biosensor using $\beta$-galactosidase modified by glutaraldehyde as the immobilized enzyme and poly- $\beta$-CDP as the carrier was prepared, and the response characteristic of the sucrose biosensor was found to be ideal. The sucrose biosensor has a good linear relationship in the sucrose concentration range of $0-3 \mathrm{~g} / \mathrm{dL}$. In particular, in the range of $0-2 \mathrm{~g} / \mathrm{dL}$, the correlation coefficient reached 0.9996 and it retained its sensitivity after $7 \mathrm{~d}$ continuous use. The physical and chemical properties, enzyme kinetics, Michaelis-Menten equation and substrate affinity of the $\beta$-galactosidase modified by glutaraldehyde should also be systematically studied for further application.

\section{Acknowledgements}

This work was supported by the National Natural Science Foundation of the People's Republic of China (No. 30871951) and the 'Eleventh Five-Year' National Science and Technology Support Program of China (No. 2006BAD04A08). 


\section{References}

1 V. Gekas and M. Lopez-Leiva: Process Biochem. (Oxford, U.K.) 20 (1985) 2.

2 M. Maksimainen, N. Hakulinen, J. M. Kallio, T. Timoharju, O. Turunen and J. Rouvinen: J. Struct. Biology 174 (2011) 156.

3 J. H. German: Milk Powders for the Future (Dunmore Press, Palmerston North, New Zealand, 1997) p. 81.

4 Q. Husain: Crit. Rev. Biotechnol. 30 (2010) 41.

5 D. F. M. Neri, V. M. Balcăo, F. O. Q. Dourado, J. M. B. Oliveira, L. B. Carvalho Jr. and J. A. Teixeira: J. Mol. Catal. B: Enzym. 70 (2011) 74.

6 P. Jochems, Y. Satyawali, S. Van Roy, W. Doyen, L. Diels and W. Dejonghe: Enzyme Microb. Technol. doi:10.1016/j.enzmictec.2011.06.010.

7 Q. Husain, S. Ahmed Ansari, F. Alam and A. Azam: Int. J. Biol. Macromol. 49 (2011) 37.

8 C. Z. Guidini, J. Fischer, L. N. S. Santana, V. L. Cardoso and E. J. Ribeiro: Biochem. Eng. J. $52(2010) 137$.

9 Q. Z. K. Zhou and X. D. Chen: Biochem. Eng. J. 9 (2001) 33.

10 E. Katchalski: Trends Biotechnol. 11 (1993) 471.

11 Y. Kurokawa, K. Suzuki and Y. Tamai: Biotechnol. Bioeng. 59 (1998) 651.

12 S. Sungur and U. Akbulut: J. Chem. Technol. Biotechnol. 59 (1994) 303.

13 C. Carpio, P. Gonzalez, J. Ruales and F. Batista-Viera: Food Chem. 68 (2000) 403.

14 Q. Shen, R. Yang, X. Hua, F. Ye, W. Zhang and W. Zhao: Process Biochem. 46 (2011) 1565.

15 M. Ammam and J. Fransaer: Sens. Actuators, B 148 (2010) 583.

16 C. Z. Guidini, J. Fischer, M. M. de Resende, V. L. Cardoso and E. J. Ribeiro: J. Mol. Catal. B: Enzym. 71 (2011) 139.

17 S. A. Ansari and Q. Husain: J. Mol. Catal. B: Enzym. 70 (2011) 119.

18 Y. S. Song, J. H. Lee, S. W. Kang and S. W. Kim: Food Chem. 123 (2010) 1.

19 P. Lozano, D. Combes and J. L. Iborra: J. Biotechnol. 35 (1994) 9.

20 V. Athes and D. Combes: Enzyme Microb. Technol. 22 (1998) 532.

21 L. Heremans and K. Heremans: Biochim. Biophys. Acta 999 (1989) 192.

22 A. Z. M. Badruddoza, A. S. H. Tay, P. Y. Tan, K. Hidajat and M. S. Uddin: J. Hazard. Mater. 185 (2011) 1177.

23 Y. J. Li, C. H. Song, L. Y. Zhang, W. B. Zhang and H. G. Fu: Talanta 80 (2010) 1378.

24 W. Kutner, W. Storck and K. Doblhoter: J. Inclusion Phenom. Mol. Recognit. Chem. 13 (1992) 257.

25 V. Athès, R. Lange and D. Combes: Eur. J. Biochem. 255 (1998) 206.

26 F. X. Schmid: Protein Structure: A Practical Approach, ed. T. E. Creighton (IRL Press, Oxford, 1989) p. 251.

27 C. A. Royer: Protein Stability and Folding, vol. 40, ed. B. A. Shirley (Humana Press, Totowa, 1995) p. 65.

28 K. Wallenfels and O. P. Malhotra: The Enzymes, ed. P. D. Boyer (Academic Press, New York, 1960) p. 409.

29 J. P. Presnosil, E. Stuker and J. R. Borne: Biotechnol. Bioeng. 30 (1987) 1019.

30 N. R. Singh: J. Mol. Liq. 152 (2010) 19.

31 A. Reddy and F. Maley: J. Biol. Chem. 271 (1996) 13953.

32 A. White, D. Tull, K. Johns, S. G. Withers and D. R. Rose: Nat. Struct. Biol. 3 (1996) 149. 